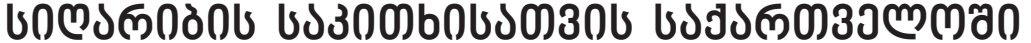

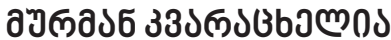

https://doi.org/10.35945/gb.2017.03.025

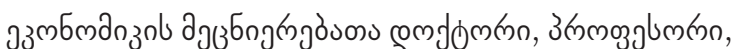

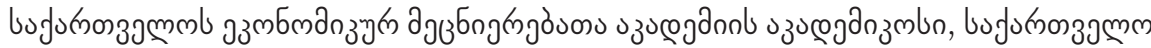

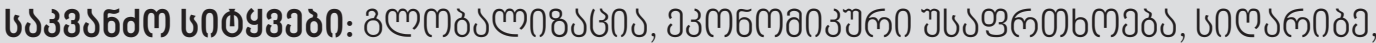

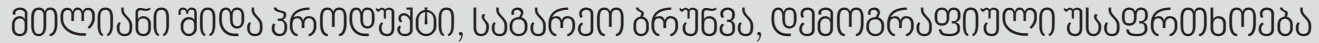

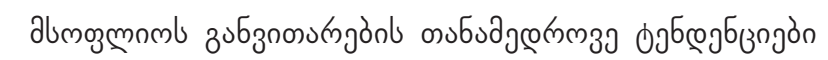

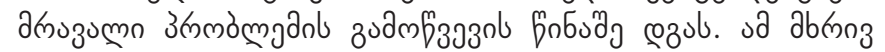

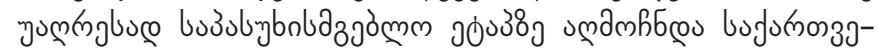

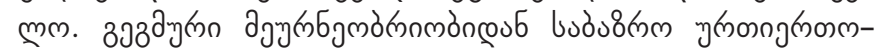

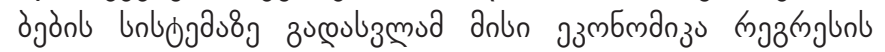

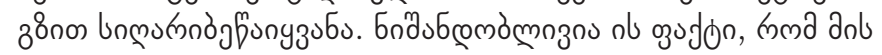

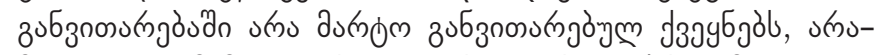

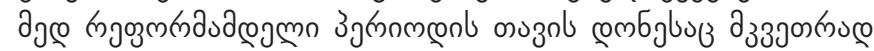
hodmknho.

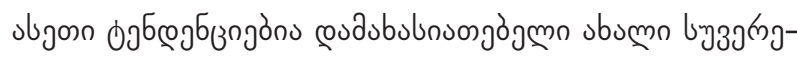

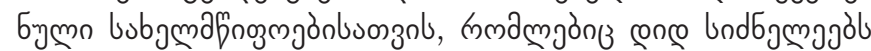

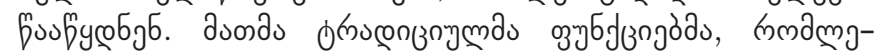

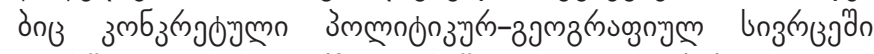

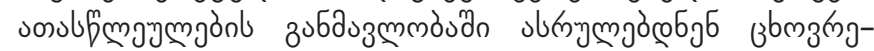

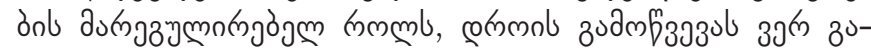

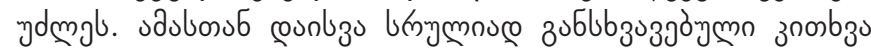

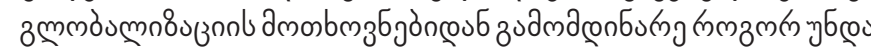

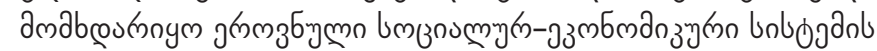

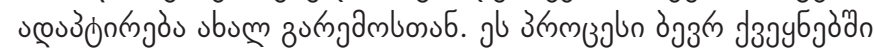

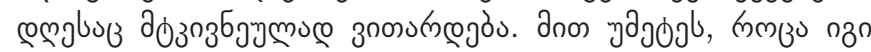

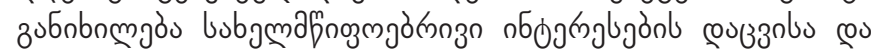

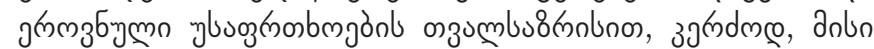

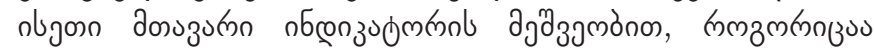

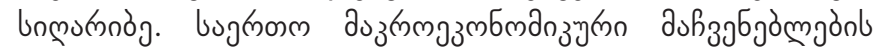

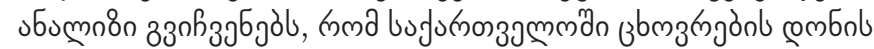

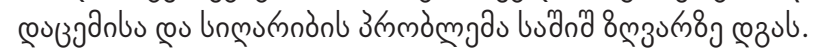

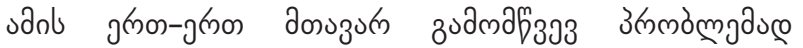

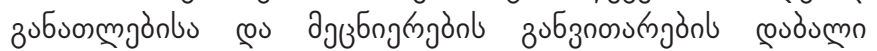

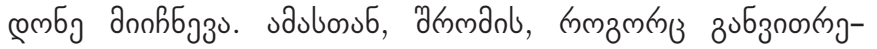

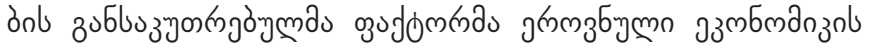

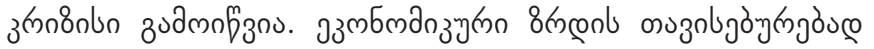

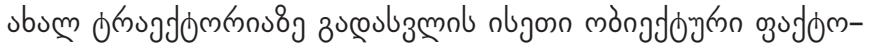

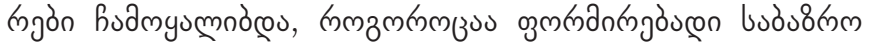

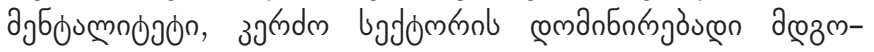

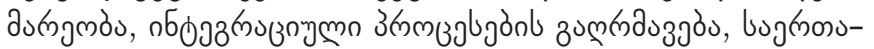

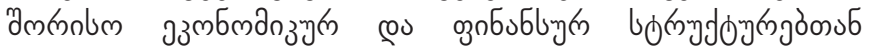

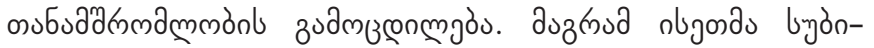

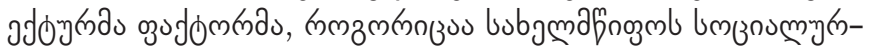

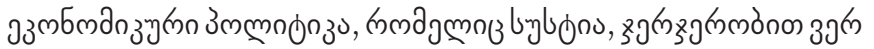

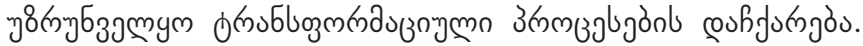

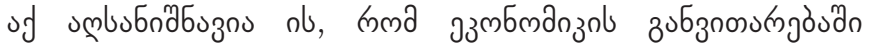

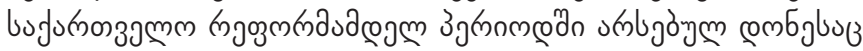

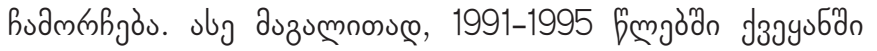

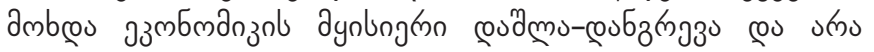

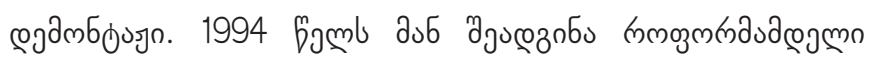

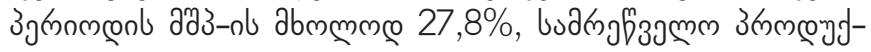

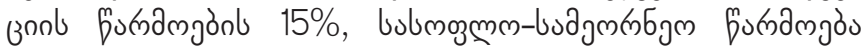

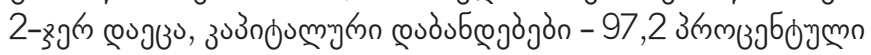

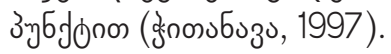

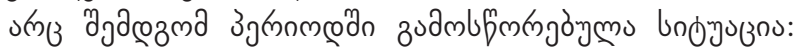

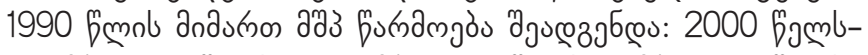
38,1\%, 2003 6amb - 46,3\%, 2007 Gamb-65\%, 2008 6jmb-

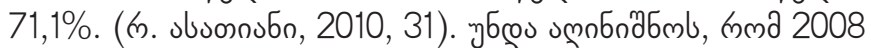

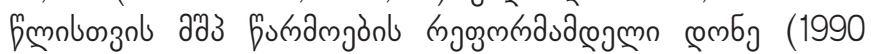

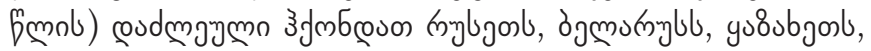

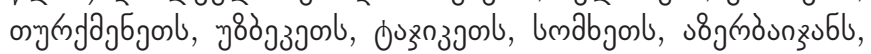

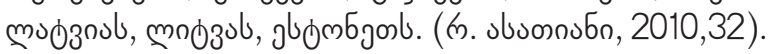

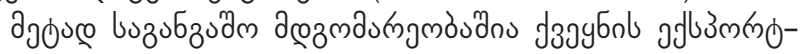

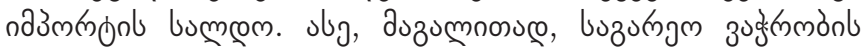

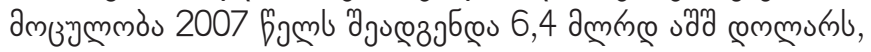

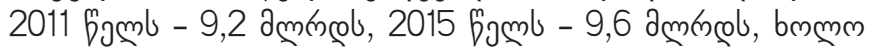

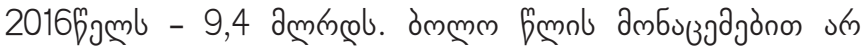

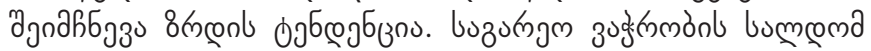

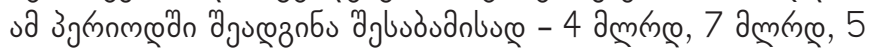

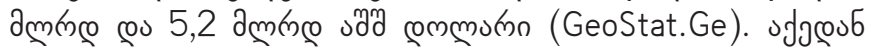

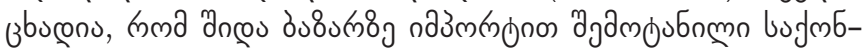

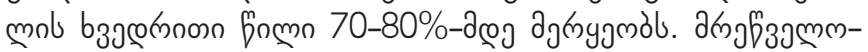

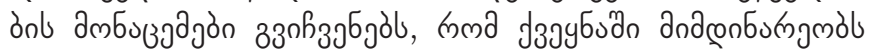

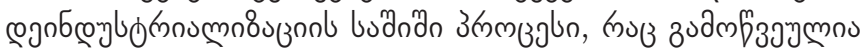

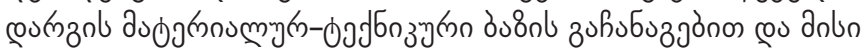

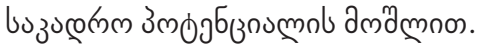

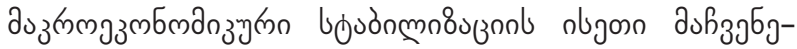

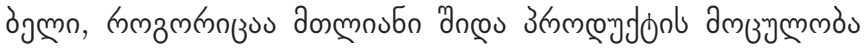

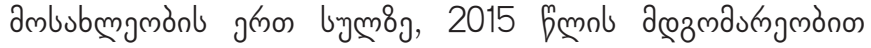

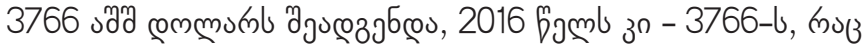

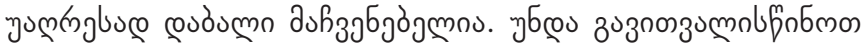

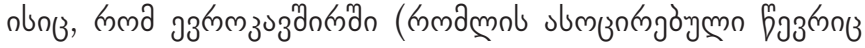

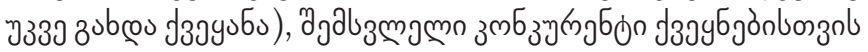

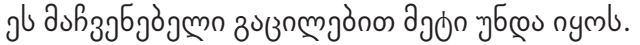

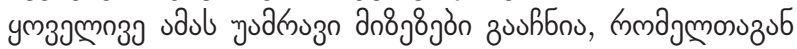

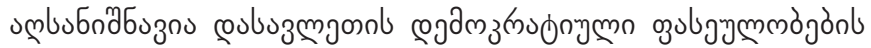

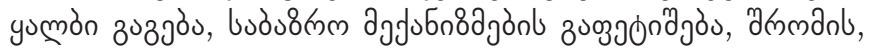

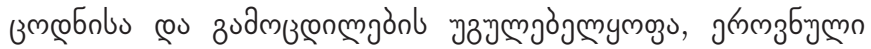

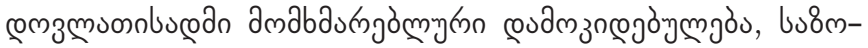
zuюmjóm

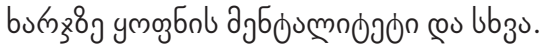

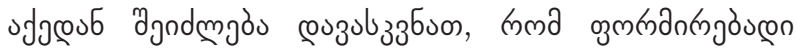

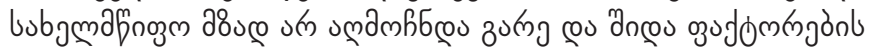




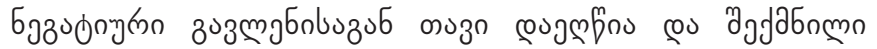

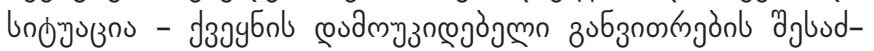

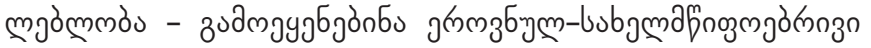

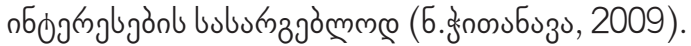

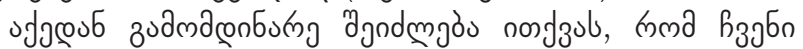

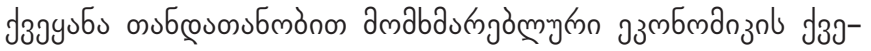
yubs begós.

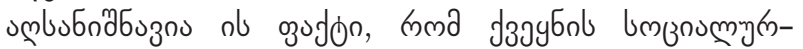

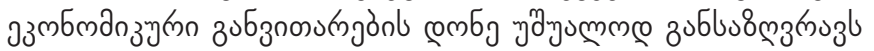

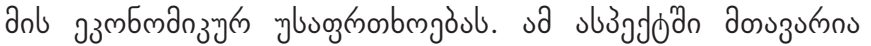

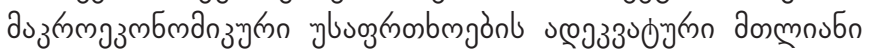

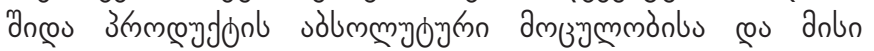

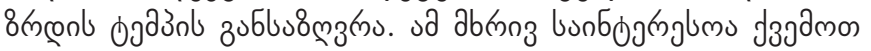

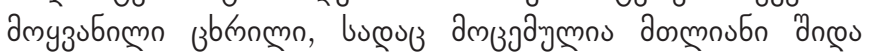

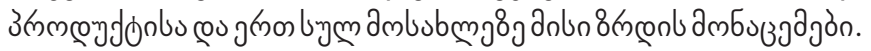

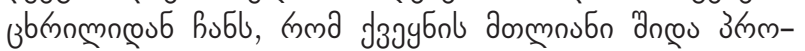

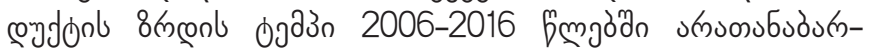

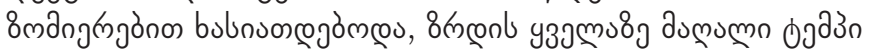

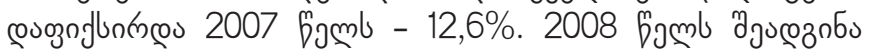

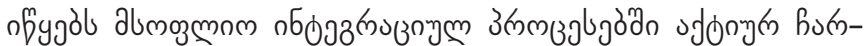

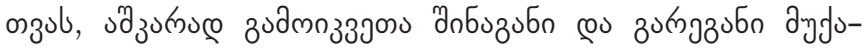

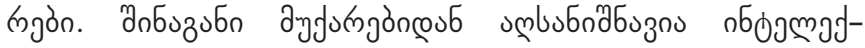

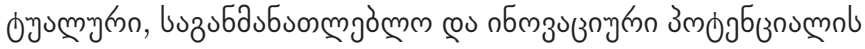

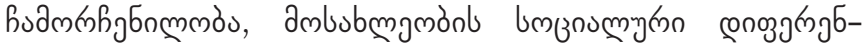

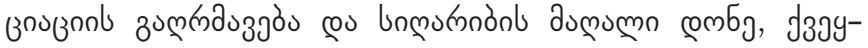

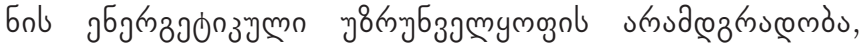

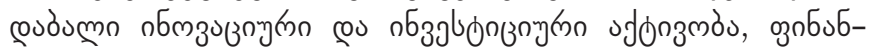

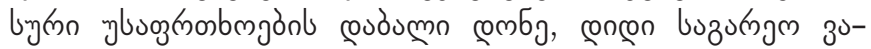

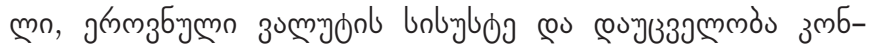

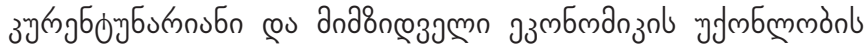

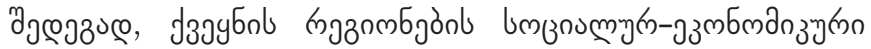

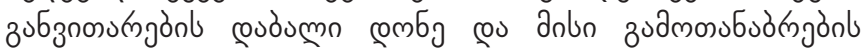

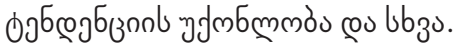

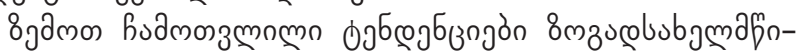

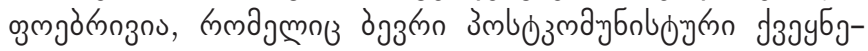

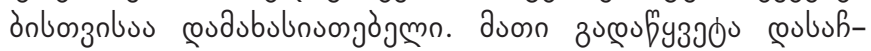

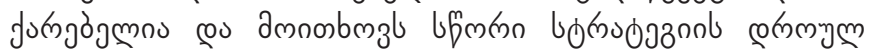

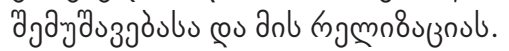

obrongon 1

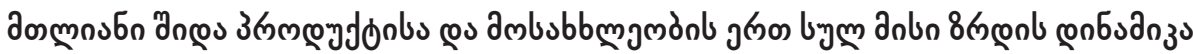

\begin{tabular}{|l|l|l|l|l|l|l|l|l|l|l|}
\hline $\mathbf{2 0 0 6} 6$. & $\mathbf{2 0 0 7} 6$. & $\mathbf{2 0 0 8} 6$. & $\mathbf{2 0 0 9} 6$. & $\mathbf{2 0 1 0} 6$. & $\mathbf{2 0 1 1 6 .}$ & $\mathbf{2 0 1 2 6 .}$ & $\mathbf{2 0 1 3} \mathbf{6 .}$ & $\mathbf{2 0 1 4} \mathbf{6 .}$ & $\mathbf{2 0 1 5 6 .}$ & $\mathbf{2 0 1 6 6}$ \\
\hline $9,40 \%$ & $12,60 \%$ & $2,40 \%$ & $-3,70 \%$ & $6,20 \%$ & $7,20 \%$ & $6,40 \%$ & $3,40 \%$ & $4,60 \%$ & $2,80 \%$ & $2,70 \%$ \\
\hline 1763,5 & 2314,6 & 2921,1 & 2455,2 & 2623 & 3230,7 & 3523,4 & 3599,6 & 3676,2 & - & - \\
\hline
\end{tabular}

fyurno: geostat.ge

3bronmo 2

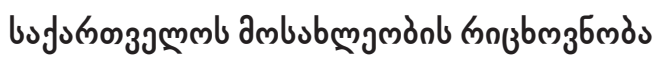

\begin{tabular}{|c|c|c|c|c|c|c|c|c|c|c|}
\hline \multicolumn{11}{|c|}{ 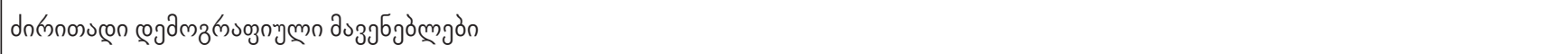 } \\
\hline & 2006 & 2007 & 2008 & 2009 & 2010 & 2011 & 2012 & 2013 & 2014 & 2015 \\
\hline 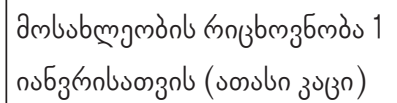 & 4401.3 & 4394.7 & 4382.1 & 4385.4 & 4436.4 & 4469.2 & 4497.6 & 4483.8 & 4490.5 & 3729.5 \\
\hline
\end{tabular}

fysøm: geostat.ge

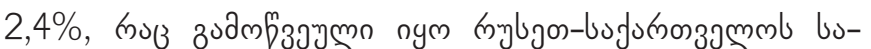

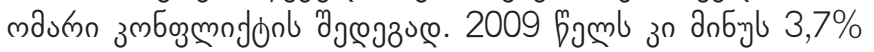

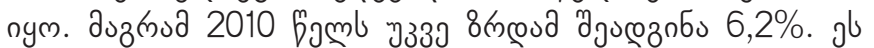

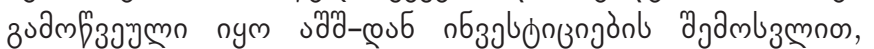

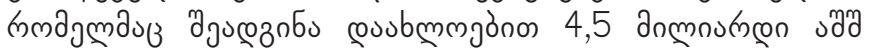

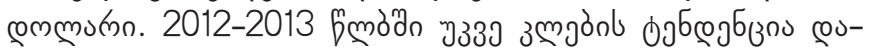

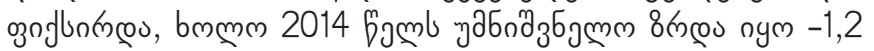

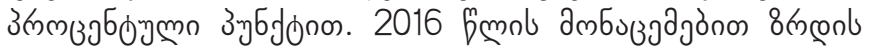

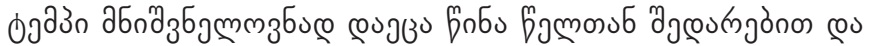

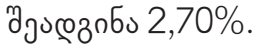

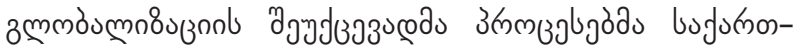

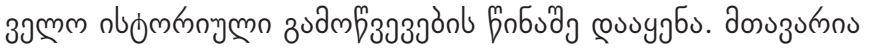

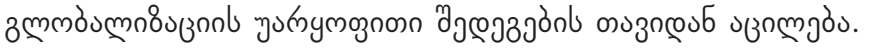

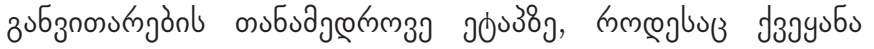

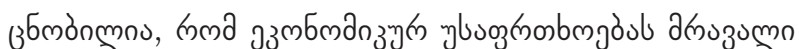

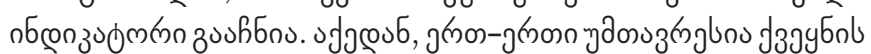

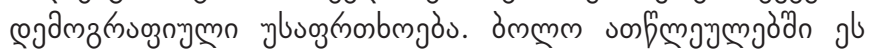

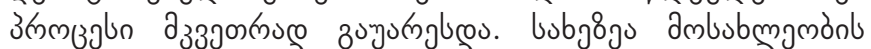

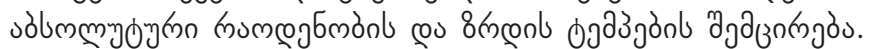

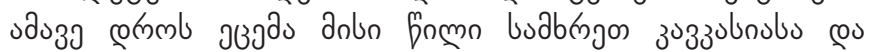

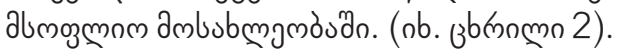

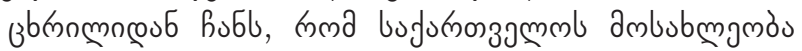

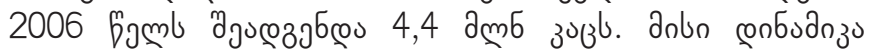

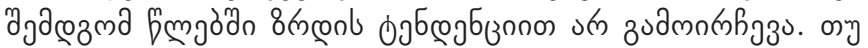

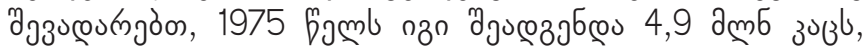

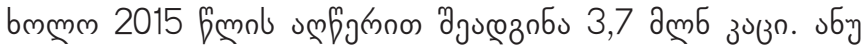

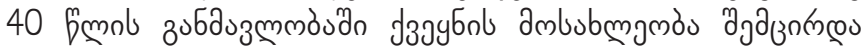

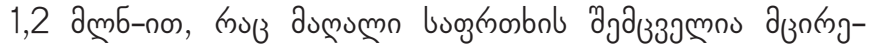




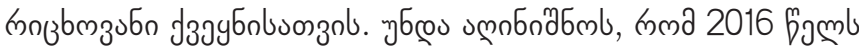

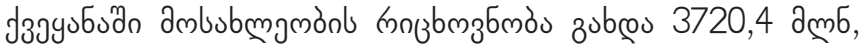

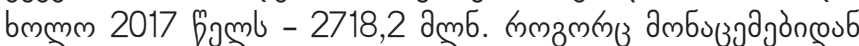

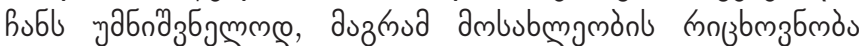

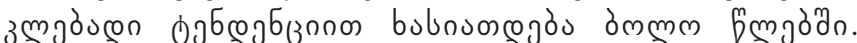

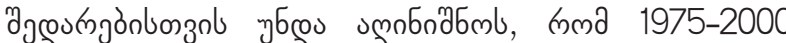

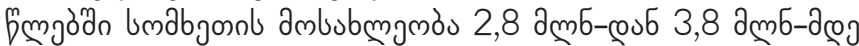

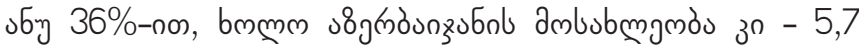

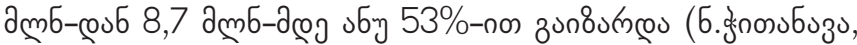

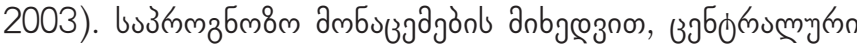

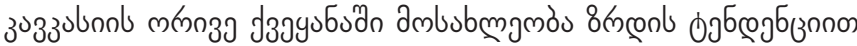

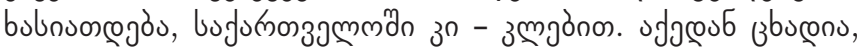

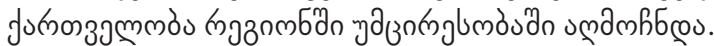

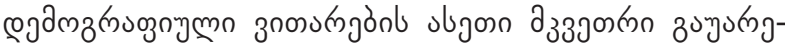

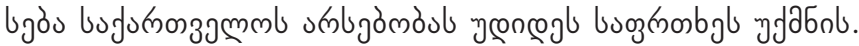

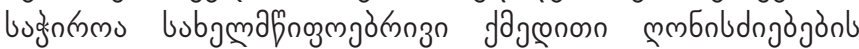

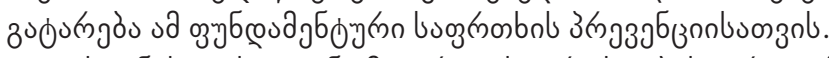

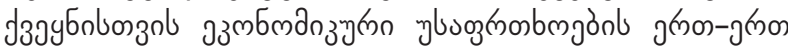

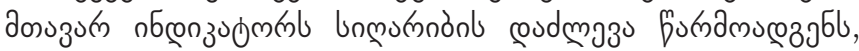

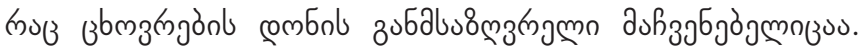

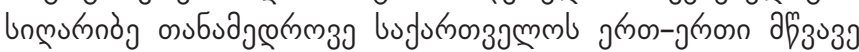

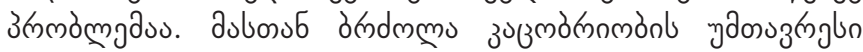

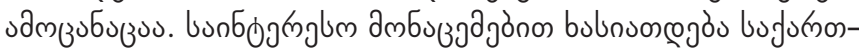

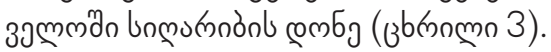

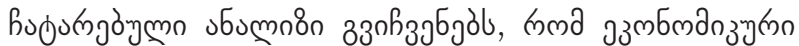

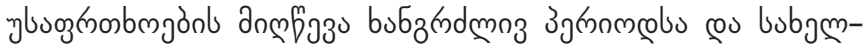

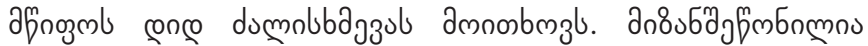

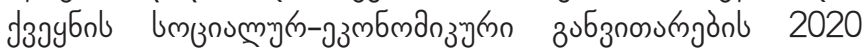

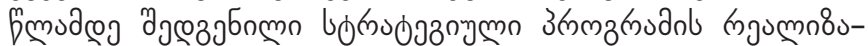

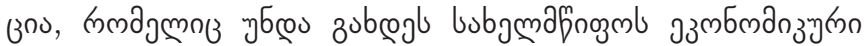

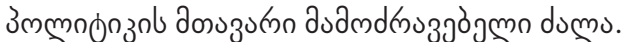

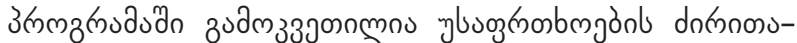

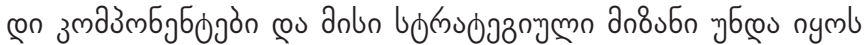

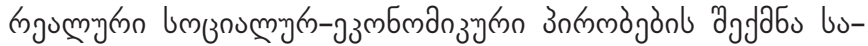

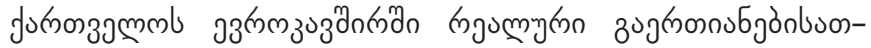

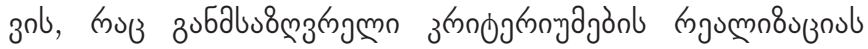
उचmolbamoll.

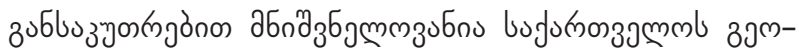

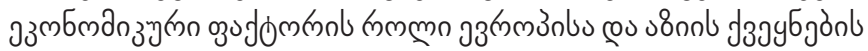

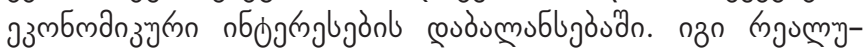

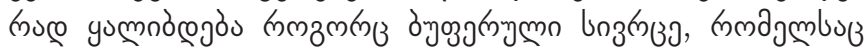

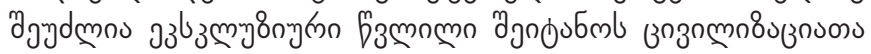

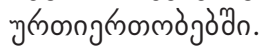

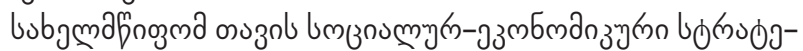

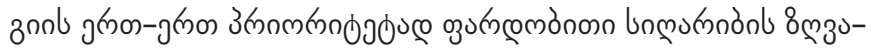

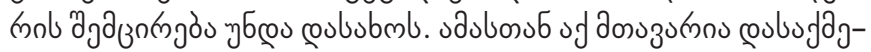

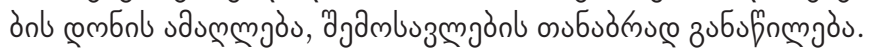

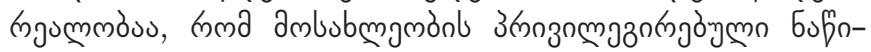

3brongno 3

\begin{tabular}{|c|c|c|c|c|c|c|c|c|}
\hline & 2007 & 2008 & 2009 & 2010 & 2011 & 2012 & 2013 & 2014 \\
\hline 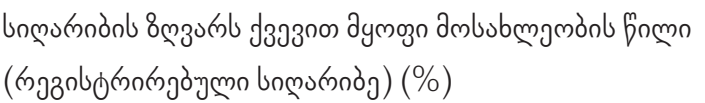 & 6.4 & 8.4 & 9.9 & 9.7 & 9.2 & 9.7 & 9.7 & 11.6 \\
\hline
\end{tabular}

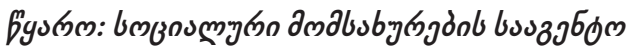

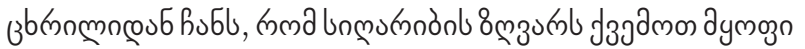

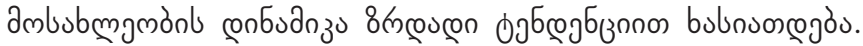

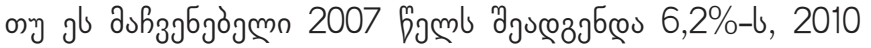

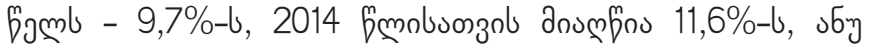

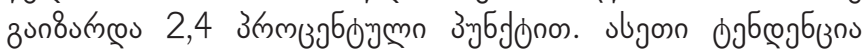

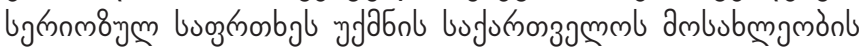

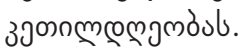

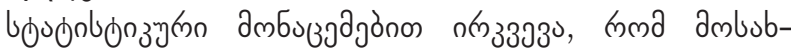

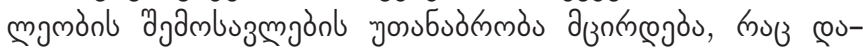

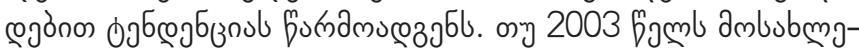

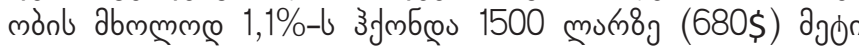

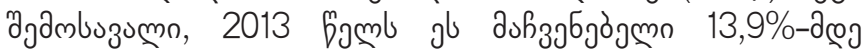

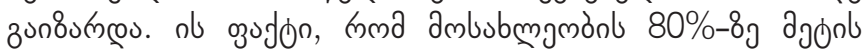

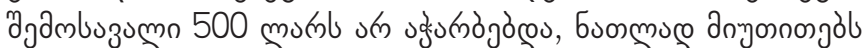

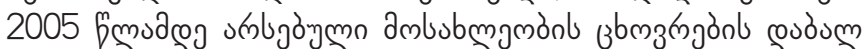

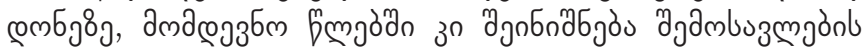

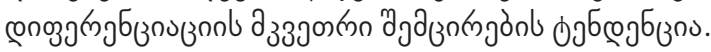

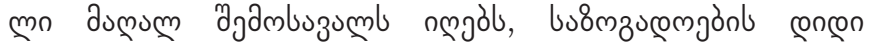
бuf̧nm

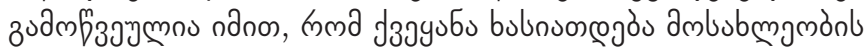

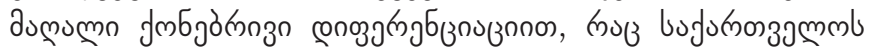

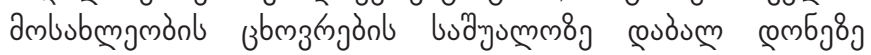

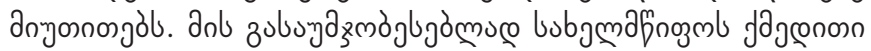

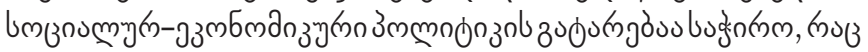

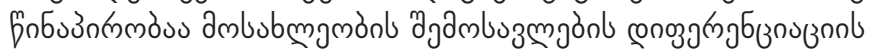

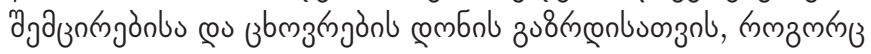
jumujnl, ubjag lmogmal ambubmgmósan.

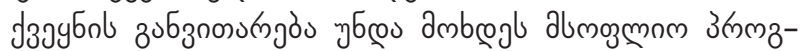

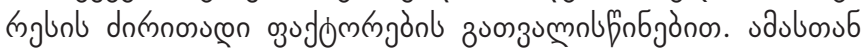

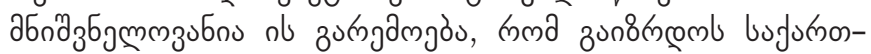

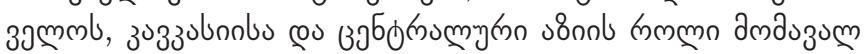

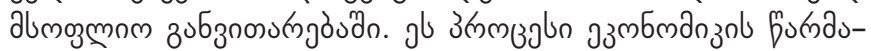

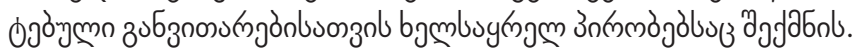




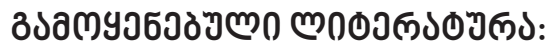

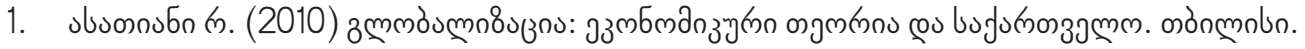

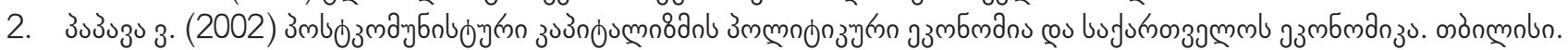

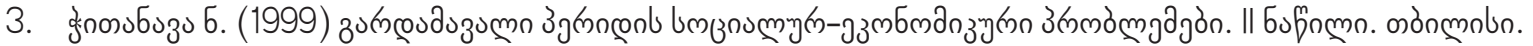

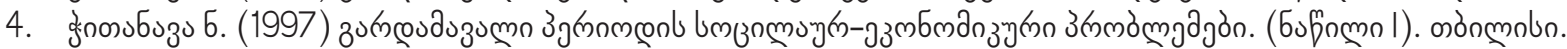

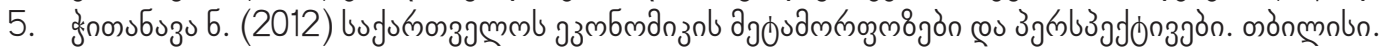

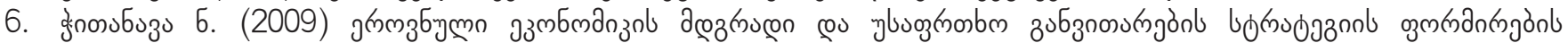

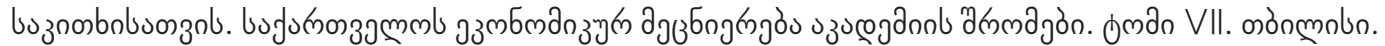

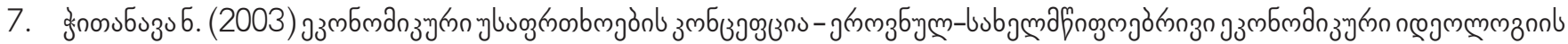

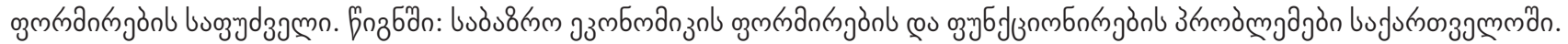

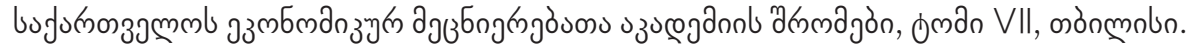

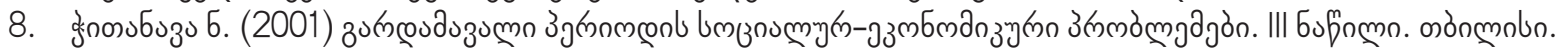

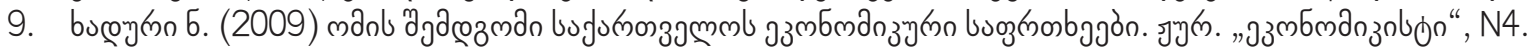




\section{POVERTY ISSUE IN GEORGIA}

MURMAN KVARATSKHELIA

https://doi.org/10.35945/gb.2017.03.025

Doctor of Economic sciences, Professor,

Academician of Academy Georgian Economic Sciences, Georgia

KEYWORDS: GLOBALIZATION, ECONOMIC SECURITY, POVERTY, GROSS PRODUCT FOREIGN TURNOVER, DEMOGRAPHIC SECURITY

\section{SUMMARY}

The article discusses the challenges facing Georgia during the globalization period. The peculiarities of transition to the principles of the market economy of the country, analysis of macroeconomic indicators, especially dynamics of GDP (gross domestic product) in recent years. In addition, the essence of economic security and the importance of the country's economic development stabilization process is analyzed.

The main issues that the article highlights are economic security indicators such as demographic safety, economic and economic development trends, economic security, poverty level indicators, population revenue trends, relative poverty and employment issues. 